\title{
Risk factors for skin lesions on the necks of Norwegian dairy cows
}

\author{
C. Kielland, ${ }^{*}$ K. E. Bøe,† A. J. Zanella, ${ }^{*} \dagger$ and O. Østerås* \\ *Department of Production Animal Clinical Sciences, Norwegian School of Veterinary Science, 0033 Oslo, Norway \\ †Department of Animal and Aquacultural Sciences, Norwegian University of Life Sciences, 1439 Ås, Norway
}

\section{ABSTRACT}

Physical restrictions at the feed barrier may cause skin lesions, especially on the necks of cows. Thus, some aspects of the functionality of feed barrier design can be assessed by observing skin lesions on the necks of dairy cattle. In this study, 232 herds, mainly of the breed Norwegian Red (94\%), were investigated between September 2006 and June 2007. The herds were categorized into 2 groups. One data set, based on 1,148 cows (115 herds), was from farms using feed barriers with post-and-rail designs ( 86 herds) and combinations of barriers (29 herds). The second data set, which included 1,168 cows (117 herds), was from farms using only vertical feed barriers such as tombstone, diagonal, and headlock. Skin lesions were observed on the necks of $21 \%$ of the 2,335 cows observed. Forty-two percent of cows had neck lesions in herds with post-and-rail barriers, whereas $4 \%$ of cows had neck lesions in herds with vertical barriers and 30\% of cows had neck lesions in herds with a combination of both horizontal and vertical barriers. Alternating logistic regression was used to identify factors associated with skin lesions on the necks of cows. The estimates were transformed into odds ratios (OR). In herds in which post-and-rail design barriers were used, the following risk factors were associated with skin lesions: manger front lower than $63 \mathrm{~cm}$ versus higher $(\mathrm{OR}=3.6)$, no feed stalls versus feed stalls (OR $=10.9)$, mixed rations versus no mixed ration $(\mathrm{OR}=$ $3.8)$, cows later than $30 \mathrm{DIM}$ versus earlier $(\mathrm{OR}=1.9)$, cows with low milk production versus those producing $1,000 \mathrm{~kg}$ higher $(\mathrm{OR}=1.4)$, feeding frequency of less than 3 times daily versus 3 and more times daily $(\mathrm{OR}=$ $1.9)$, using only post-and-rail feed barriers $(\mathrm{OR}=1.8)$ versus using combinations, and farmer disagreement with the statement "animals experience physical pain as humans do" $(\mathrm{OR}=1.9)$ versus agreement. Diagonal barriers, categorized as vertical barriers, increased the association of skin lesions with increasing manger front heights. Feed barrier design was associated with skin lesions on the necks of cows, particularly for barriers of

Received November 13, 2009.

Accepted May 18, 2010.

${ }^{1}$ Corresponding author: camilla.kielland@nvh.no a post-and-rail design. To minimize the risk of neck lesions, the top rail height of post-and-rail barriers should be above $109 \mathrm{~cm}$, especially for cows taller than $126 \mathrm{~cm}$, and the manger front should not be lower than $63 \mathrm{~cm}$. Feed stalls, feeding frequency of 3 or more times daily, and the feeding of unmixed rations were also identified as preventive factors.

Key words: dairy cow, skin lesion on neck, feed barrier, farmer attitude

\section{INTRODUCTION}

The occurrence of skin lesions has been widely used in on-farm dairy cow welfare assessments (Main et al., 2003; Haskell et al., 2006; Thomsen et al., 2007). Previous studies have focused on hock and knee lesions in relation to free stall base design (Busato et al., 2000; Weary and Taszkun, 2000; Kielland et al., 2009). Skin lesions in cattle are likely to occur at areas of the body where there are protrusions that are in repeated contact with elements of the housing (Weary and Taszkun, 2000). For example, when animals lie down, soft tissue is compressed between the lying surface and bony protrusions such as between the tarsal bones, resulting in an interruption to perfusion of the tissue (Zurbrigg, 2006). Similarly, physical restrictions at the feed barrier may cause skin lesions, especially on the neck. Therefore, one aspect of the functionality of feed barrier design may be assessed by recording skin lesions on the necks of dairy cattle. The prevalence of skin lesions on necks of dairy cattle varies widely and has been reported to range from $1 \%$ in Switzerland (Busato et al., 2000) to $4 \%$ in Canada (Zurbrigg et al., 2005) to up to $50 \%$ in the United Kingdom (Huxley et al., 2004).

Dumelow (1987) measured the pressure applied to horizontal feed rails situated at different heights. Pressures of more than 2,000 $\mathrm{N}$ have been measured between a cow and feed barrier when food was located at the limit edge of the cow's reach. The edge of the reaching area was measured to have a mean value of $88 \mathrm{~cm}$ (Dumelow, 1987). Dumelow (1987) and Hansen et al. (2001) did not record skin lesions in their studies but nevertheless made inferences about pressures leading to injuries. We are aware of only a single previous 
study addressing both neck lesions and detailed feed barrier measurements, and this was performed in tie stall barns in Ontario, Canada (Zurbrigg et al., 2005). These authors found that the median tie-rail height was $96.5 \mathrm{~cm}$, coinciding with older recommendations that focused on the design of stalls to facilitate stall cleanliness. According to Zurbrigg et al. (2005), new regulations suggest that a tie-rail should be positioned at $121.9 \mathrm{~cm}$ for an average Holstein cow to prevent neck injuries.

Until now, assessments of the functionality of feed barriers have focused on cow behavior. Elevated mangers and vertical feed barriers affect cows' reaching areas and the forces on the barriers (Gjestang, 1982; Hansen et al., 2001). Other studies have reported a close relationship between cow behavior and factors such as various types of barriers, social rank, stocking density, and access to feed (DeVries et al., 2004; Endres et al., 2005; DeVries and von Keyserlingk, 2006; Huzzey et al., 2006). Few papers have investigated whether these factors are related to milk production. Thomsen et al. (2007) defined cows as loser cows using several factors, including skin lesions. Loser cows yielded between 0.64 to $2.24 \mathrm{~kg}$ of ECM less per day than nonloser cows.

The risk factors for neck lesions listed above cannot explain all the variables associated with skin lesions. Management strategies and early intervention may also play important roles in the occurrence of neck lesions. Farmers' attitudes toward their animals may affect the management of their cows both indirectly and directly (Coleman et al., 1998; Barkema et al., 1999). The human-animal relationship also influences cattle productivity and welfare (Breuer et al., 2000; Hemsworth et al., 2000). Kielland et al. (2010) assessed attitudes of dairy farmers toward cows. The rationale of including measures of farmers' attitudes in traditional epidemiological risk factor analysis rests upon the assumption that there is a relationship between human empathy, attitudes, and behavior toward animals and, ultimately, animal welfare. The attitude profiles of farmers were included in the analyses of the current study with the intention of also capturing the farmer effect and exploring whether this effect was associated with neck lesions. Thus, the aim of this study was to identify possible risk factors for neck lesions associated with feed barrier design and feeding regimen, milk production, and farmers' attitudes toward cattle.

\section{MATERIALS AND METHODS}

\section{Farm Selection}

This study was part of a larger descriptive and crosssectional project on free stall housing in Norwegian dairy herds. A list of 2,400 herds that were assumed to house cattle in free stalls was obtained from the Norwegian Dairy Herd Recording System database. In 2005, this database had records from 11,600 dairy farms (Østerås et al., 2007). A questionnaire asking for farmers' willingness to participate in the study was sent out to the 2,400 herds. Responses from the questionnaire were, after 1 reminder, obtained from 1,323 farmers (response rate of 55\%). Inclusion criteria for the study were farmers' willingness to participate, herd size $>20$ standardized cow-years (based on the year 2005), barns built between 1995 and 2005, and the presence of free stalls. Of these farms, 1,036 had free stall-loose housing systems and, of these, 232 farms met the other inclusion criteria.

\section{Study Sample}

The study sample consisted of 2,335 animals from the 232 herds. Animals observed at farm visits were selected by systematic random sampling from individual lists of all animals at the particular farm that were being milked at that time. Every third to fifth animal, according to their individual identification number, was selected, and 10 animals per herd were observed. The intention was that only cows that were lactating would be selected, but if a cow in the dry period had not been omitted from the list of animals being milked, it was assessed if selected. This was accounted for in the analyses by including DIM. The predominant breed in the study was Norwegian Red, which accounted for $94 \%$ of the animals. Of the other breeds observed, most were Norwegian Red crossbreeds.

The mean herd size of our study population was 39 (SD \pm 16$)$ in 2006, including milking cows as well as dry cows. Average milk production per cow-year in 2006 was $7,053 \mathrm{~kg}(\mathrm{SD} \pm 959)$. Summer grazing was used in $60 \%$ of herds in the months June to August. Date of visit was recorded and classified as the month of visit in the analysis.

\section{Data Collection}

Questionnaire. A questionnaire was sent out to gather information about type of farming, ownership, frequency of feeding (number of times per day that fresh feed was offered to the cows), number of feed push ups (if feed was pushed up toward the feed barrier between feeding times), type of roughage feeding systems, and whether feed stalls were present. The various roughage feeding systems were manual roughage feeding, automated feeding systems on rails, and mixed rations. Feed stalls were defined as stalls in which the animals were fed and with separation barriers between cows. 


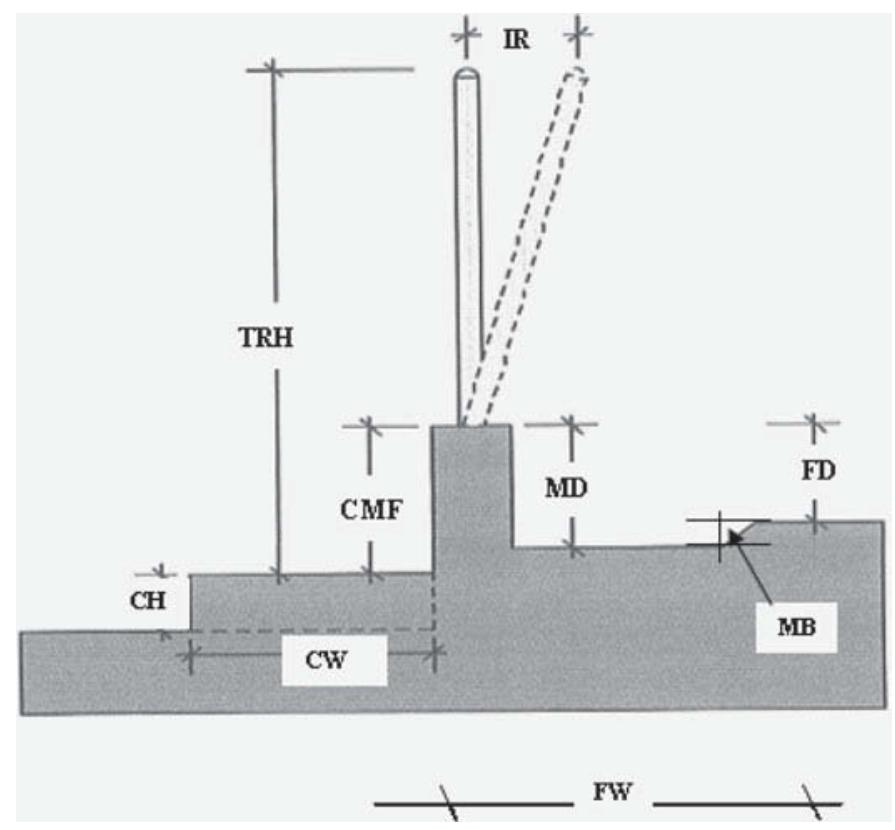

Figure 1. Measurements made on the feed barrier. TRH $=$ top rail height; IR = inclining rail (the distance from imaginary horizontal line to the top of the TRH); $\mathrm{CMF}=$ concrete manger front; $\mathrm{FD}=$ feeding table depth; $\mathrm{MD}=$ manger depth; $\mathrm{MB}=$ manger brisket; $\mathrm{FW}=$ feeding table width; $\mathrm{CH}=$ curb height; $\mathrm{CW}=$ curb width.

The attitudes of the farmers toward animals were assessed with a separate questionnaire sent out to 221 farmers (those with e-mail addresses) of the 232 farms. Farmers were requested to respond to a statement by marking on a 5-point Likert scale ranging from strongly disagree (1) to strongly agree (5). The statement was "animals experience physical pain as humans do." This statement was chosen on the basis of previous findings that related measures of attitudes to empathy and animal welfare (Kielland et al., 2010).

Farm Visits. The herds were visited once during the indoor housing period between September 2006 and June 2007 by technicians who had been trained to obtain the relevant information and measurements regarding feed barriers and feeding routines. The method used to train these technicians is described in Kielland et al. (2009).

The main types of feed barriers used in free stalls in Norway are post-and-rail (horizontal barrier), tombstone, diagonal, and headlock (vertical barriers). When more than 1 type of barrier was present representing more than $10 \%$ of barriers or barrier space, this was recorded as a combination of feed barriers. Detailed measurements of the feed barrier design (Figure 1) as well as type of barrier (Figure 2), including the area in front of the feed barrier, were collected by the technicians. The term concrete manger front (Figure 1), manger front in short, was used according to Anderson
(2008). The manger front height is the height measured from the surface on which the cows stand to the point where the upper edge of the feed barrier is fixed. The technicians also gathered information about the free stall-cubicle design, but only the height of the neck rail in these free stalls was included in the analysis.

Animal-Based Measurements. Detailed data from each herd regarding milk production and herd size, together with individual data on parity, breed, and DIM, were obtained from the Norwegian Dairy Herd Recording System database. If the cow was visited before calving, the DIM might be a negative value, with that dry period related to the coming parity. Individual cow observations included neck lesions, BCS, and shoulder height. The animals were not immobilized when these assessments were made, but all observations except the lameness score were conducted when the animal was standing still on a flat surface. The cows' necks were assessed for skin lesions over the spine between the axis atlas (first cervical vertebra) and shoulder (first thoracic vertebra) along the skin above the nuchal ligament (Dyce et al., 1996). Lesions were recorded according to the classification published by Regula et al. (2004): 1)

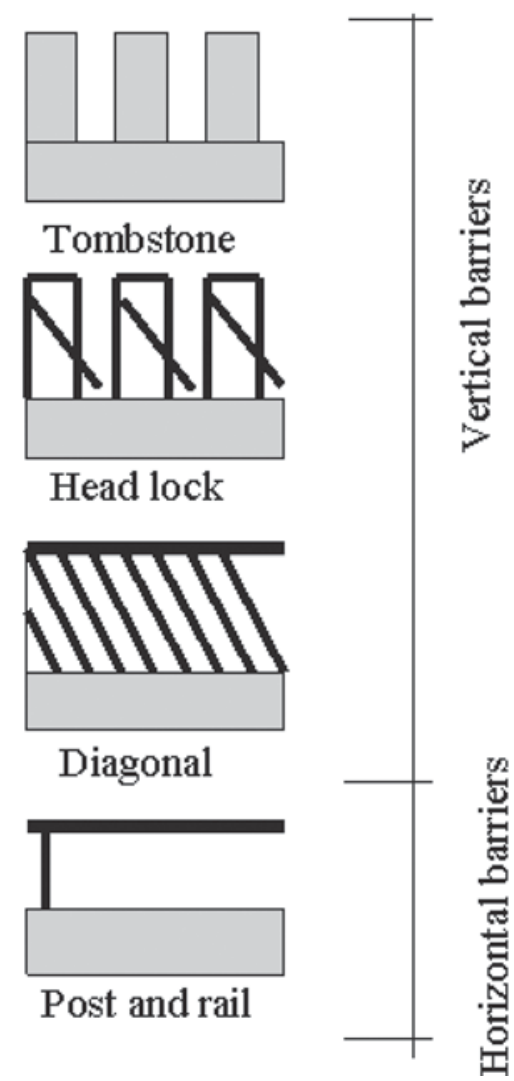

Figure 2. Different types of feed barrier designs found in 232 Norwegian free stalls. 
Zero neck lesions

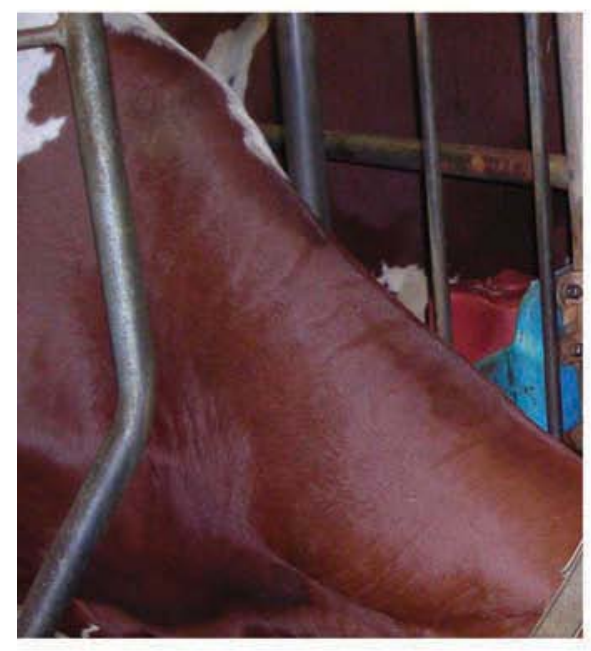

Hair loss

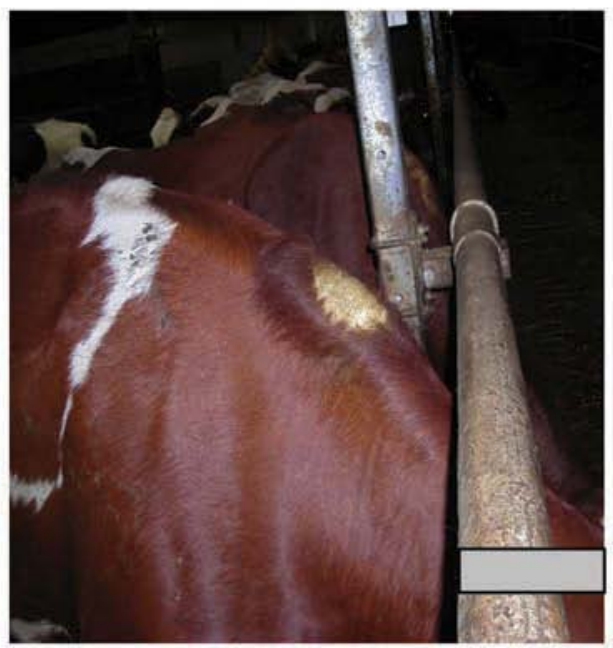

Swollen

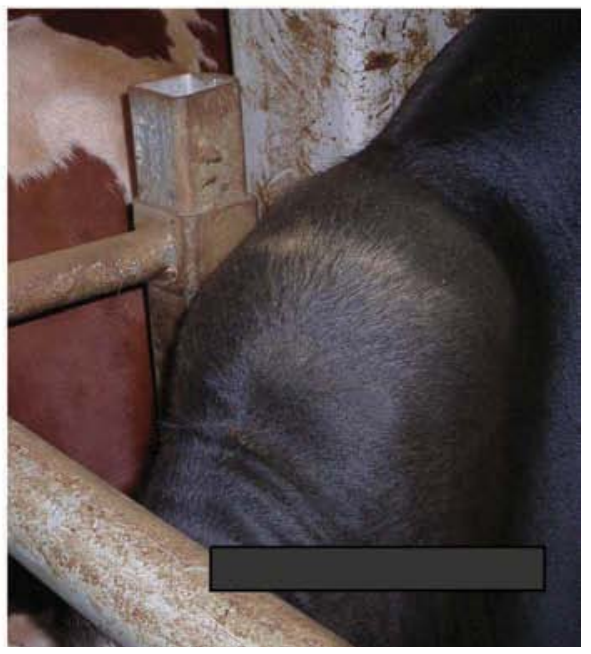

Figure 3. Lesions were classified as no observable skin change, hair loss, swollen, wounds, or open wounds (Regula et al., 2004), but only neck with no lesions, hair loss, and swollen necks were found. Color version available in online PDF.

no observable skin change, 2) hairless, 3) swollen, 4) wounds, or 5) open wounds. Figure 3 displays 3 of the 5 categories of neck lesions. Body condition score was assessed according to Edmonson et al. (1989). Shoulder height was measured in centimeters using a laser device (Robotoolz Vector 5, model RT-7600-5, Laserspesialisten, Sellebakk, Norway). The laser device was attached to a $180-\mathrm{cm}$ measuring scale. The base of the measuring scale was at the same level as the front claw, with an angle of 90 degrees to the floor, and the laser could be moved along the scale. When the laser pointed to the top of the shoulder blade, the shoulder height was recorded.

\section{Data Analysis}

Descriptive statistics of possible risk factors were performed using Excel (Microsoft Corp., Redmond, WA) and the FREQ and UNIVARIATE procedures in SAS (SAS Institute Inc., Cary, NC). Risk factors were detailed measurements of the feed barrier, details about feeding management, and individual animal-related assessments such as BCS and shoulder height. Missing data from categorical variables were accounted for by adding 1 category with missing values. Adding an extra category to categorical variables is an approach to handling missing values, especially when it is expected that the data might be biased by excluding these observations (Dohoo et al., 2009). This approach was used for analyzing the attitude statement. The reasons why farmers did not respond or did not have an e-mail address might in themselves be characteristics of a farmer and justify the inclusion of these as their own category.
Two herds were not included in the analyses because of missing values on top rail height. Shoulder heights were missing from 250 cows in different herds because of material restrictions. These cows were given a value calculated as mean shoulder height $(133.6 \mathrm{~cm})$ measured from the remaining 2,085 cows. Some of the BCS were missing $(\mathrm{n}=8)$, and these were then replaced with the mean BCS from this study. The model was tested with and without replacing the values for the missing shoulder heights, and the estimates were not affected.

An alternating logistic regression model that accounted for clustering at herd level was performed by including a LOGOR estimate (Carey et al., 1993) in the GENMOD procedure in SAS (version 9.1, SAS Institute Inc.). The general model used for estimating $\beta$ was

$$
\operatorname{logit}\left(p_{i}\right)=\beta_{0}+\beta_{1} X_{1 i s}+\ldots+\beta_{k} X_{k i s}+\mathrm{Z} \operatorname{herd}(i),
$$

where $\beta_{0}$ is the intercept and $\beta_{1} X_{1 i s}+\ldots+\beta_{k} X_{k i s}$ are fixed effects clustered on herd level, $\mathrm{Z}$ herd $(i)$. The GENMODE procedure in SAS (SAS Institute Inc.) was used to investigate the risk factors related to the absence or presence of lesions on the necks of the cattle using binomial distribution with loglink function and Wald chi-squared type 3 for significance testing.

The outcome variable chosen was any type of skin lesion on the neck. Lesions were classified as hairless, swollen, wound, or open wound (1) or as no lesions (0). Both hair loss and swollen necks were included in the same group to increase the robustness of the model because swollen necks were observed only infrequently. 
Table 1. Distribution of various measures related to feeding management, type of feed barrier, and the distributions of the classifications used in logistic analysis

\begin{tabular}{|c|c|c|}
\hline Variable and classification & n (herd) & $\%$ \\
\hline \multicolumn{3}{|l|}{ Feed barrier type ${ }^{1}$} \\
\hline Post-and-rail design & 86 & 37.1 \\
\hline Diagonal & 9 & 3.9 \\
\hline Headlock & 25 & 10.8 \\
\hline Tombstone & 63 & 27.2 \\
\hline Post-and-rail design and headlock & 25 & 10.8 \\
\hline Diagonal and headlock & 4 & 1.7 \\
\hline Tombstone and diagonal & 16 & 6.9 \\
\hline Post-and-rail design and tombstone & 4 & 1.7 \\
\hline \multicolumn{3}{|l|}{ Feed stall ${ }^{2}$} \\
\hline Yes & 21 & 9.1 \\
\hline No & 211 & 91.0 \\
\hline \multicolumn{3}{|l|}{ Mixed ration } \\
\hline Yes & 18 & 7.8 \\
\hline No & 178 & 76.7 \\
\hline Missing & 36 & 15.5 \\
\hline \multicolumn{3}{|l|}{ Feeding frequency ${ }^{3}($ times/d) } \\
\hline$\geq 3$ & 129 & 55.6 \\
\hline$\leq 2$ & 57 & 24.6 \\
\hline Missing & 46 & 19.8 \\
\hline \multicolumn{3}{|l|}{ Feed push ups ${ }^{4}$} \\
\hline 1 time & 122 & 52.6 \\
\hline No & 38 & 16.4 \\
\hline Missing & 72 & 31.0 \\
\hline
\end{tabular}

${ }^{1}$ The classification is based on the barrier being a horizontal type, vertical type, or a combination of 2 types. In the category combining the 2 main types, the second type had to be present in more than $10 \%$ of the feeding space.

${ }^{2}$ Stalls in which the animals were fed and with separation barriers between cows.

${ }^{3}$ Number of times fresh feed was presented to the cows.

${ }^{4}$ Whether feed was pushed up toward the feed barrier between feeding times.

An ordinal outcome model was tested but did not provide more information.

Linearity between the outcome and the dichotomous predictor was investigated with graphs using a logit function in STATA (Stata SE/10 for Windows, Stata Corp., College Station, TX). Continuous variables that did not have a linear relationship with the outcome were transformed into categorized variables according to their percentiles or quartiles $(10,25,50,75$, or $90 \%)$. Other variables were transformed either into ordinary dummy variables or into hierarchical dummy variables. First, each explanatory variable was tested separately, including random effects of herd, and a crude odds ratio was calculated. Variables with a $P$-value $<0.20$ within this analysis were considered in the full model. When building the full model, a forward stepwise technique was used, starting with the variables with the lowest $P$-values from the separate variable analysis. Thus, any distortion and confounding could be observed as each variable was included. Confounding variables were tested by running the model with and without that variable. The variables giving the best fit were chosen.
If variables were strongly correlated, only one of these variables was included. Goodness of fit for each model was evaluated by means of $\Delta$ deviance.

\section{RESULTS}

\section{General Management}

Detailed measurements of feeding management and other herd-level variables have been tabulated (Table 1). Most of the herds were managed by multiple farmers $(\mathrm{n}=104)$, and few herds were organic $(\mathrm{n}=11)$.

\section{General Feed Barrier Design and Feeding Regimens}

Post-and-rail feed barriers were exclusively used in $37 \%$ of the herds. Vertical barriers were recorded in $50 \%$ of the herds, and $13 \%$ used a combination of both horizontal and vertical barriers. In total, 872 cows were housed in free stall housing with post-and-rail feed barriers, 1,168 cows were housed in free stall housing with vertical barriers, and 295 cows were housed in housing with a combination of feed barrier types. A summary of the detailed measurements performed on the feed barriers monitored in the current study is presented (Table 2). None of the herds had a feed table width less than a cow's reaching area of $88 \mathrm{~cm}$. Only $6 \%$ of farms that had post-and-rail barriers had an inclining rail of $20 \mathrm{~cm}$. A top rail height above $126 \mathrm{~cm}$ was recorded in $52 \%$ of the herds. The mean height of manger fronts in our study was $50 \mathrm{~cm}$. The number of feeding places per cow was 0.91 (range $=0.35-2.2$ ). The mean space allowance at the feed barrier was $63 \mathrm{~cm} / \mathrm{cow}$ (range $=$ $24-150 \mathrm{~cm}$ ). Almost $67 \%$ of farms had a curb against the feed barrier, marked as curb height in Figure 1. Mixed rations were used in 18 farms, 178 farms used other types of roughage feeding systems, and 36 farms were categorized as missing because farmers did not answer the question.

\section{Animal-Based Measurements}

Mean milk production in herds with horizontal barriers was $6,934 \mathrm{~kg}$ (range $=4,050-8,995 \mathrm{~kg}$ ). Mean milk production in herds with vertical barriers was $7,118 \mathrm{~kg}$ (range $=3,224-9,249 \mathrm{~kg}$ ). Shoulder height ranged from 119 to $150 \mathrm{~cm}$, with a mean of $133.6 \mathrm{~cm}$. Mean DIM was 138.0, with a range from -60 to 445 .

The overall prevalence of neck lesions was $21 \%$, with a median prevalence of $10 \%$. Of the herds visited, no neck lesions were present on cows in 112 herds (48\%) and neck lesions were present on 90 to $100 \%$ of cows and in 5 herds $(2 \%)$. The distribution of the herd prevalence among the 232 farms is presented in Figure 4. 


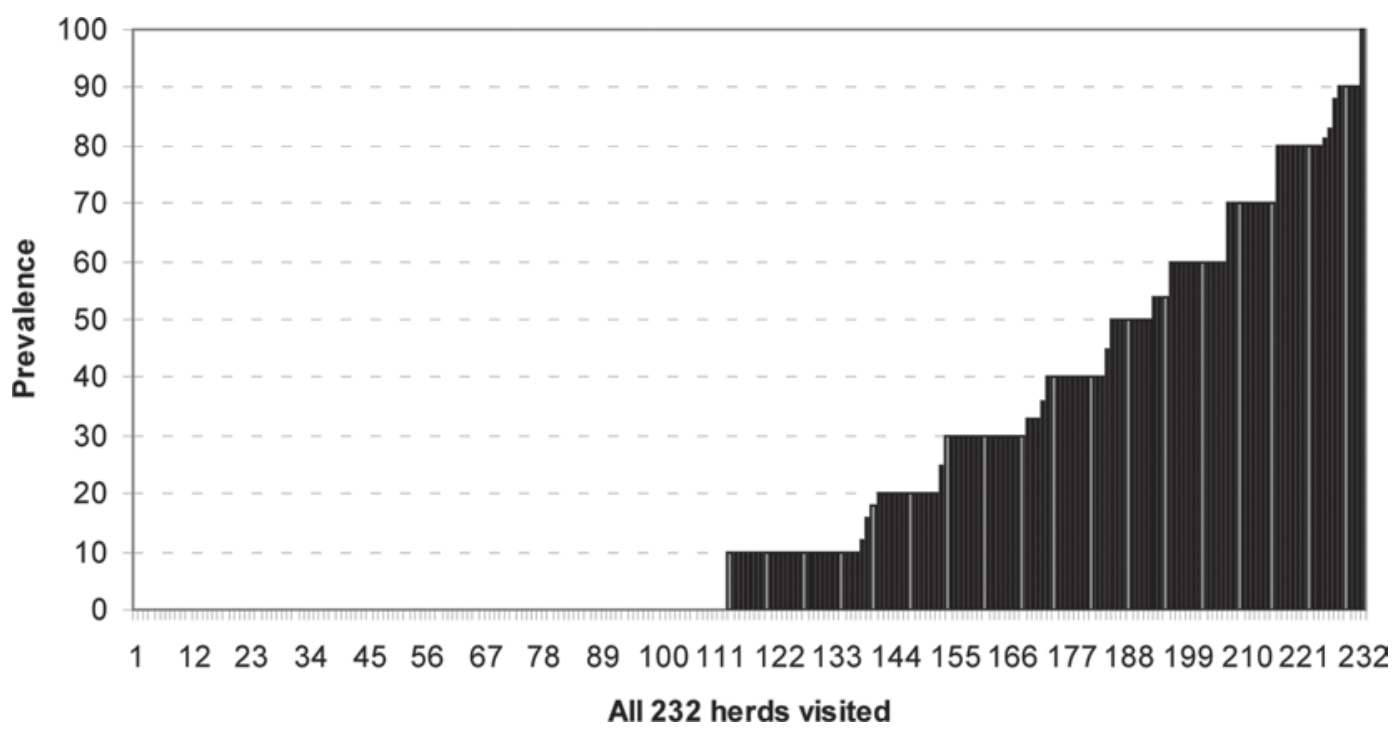

Figure 4. Distribution of the prevalence (\% of cows with neck lesions per herd) of any noticeable changes on the skin of the neck of dairy cows in 232 free stall herds.

Of the total 2,335 observed cows, $6 \%(\mathrm{n}=144$ cows) had swollen necks and $15 \%(\mathrm{n}=357$ cows) had hair loss. Farms with post-and-rail barriers accounted for $81 \%(\mathrm{n}=117)$ of the total number of cows with swelling at the neck area and $67 \%(\mathrm{n}=242)$ of the cows with hair loss. No animals were observed with wounds or open wounds. The percentages of various neck lesions according to the 3 main types of feed barriers have been tabulated (Table 3 ).

\section{Post-and-Rail Designs}

Cows from herds with post-and-rail barriers showed a $42 \%$ prevalence of neck lesions (Table 3). Detailed results from the logistic regression analyses and the direction of the estimates, odds ratio, and confidence intervals have been tabulated (Table 4). Several risk factors were significantly associated with neck lesions and are listed in order of decreasing strength of association: manger fronts lower than $63 \mathrm{~cm}$, no feed stalls, feeding mixed ration, the interaction term between shoulder heights with top rail heights (interaction term is visualized in Figure 5), 30 DIM or later, low producing cows, and feeding roughage fewer than 3 times per day. Finally, the last risk factors identified were only post-and-rail feeding barriers being used and farmers disagreeing with the statement "animals experience physical pain as humans do."

As mentioned previously, an interaction term was identified between a cow's shoulder height (per $10 \mathrm{~cm}$ ) and the top rail height. To visualize this effect, the probability of neck lesions was calculated by using the model estimates for cows with different shoulder heights, with all the categorical variables on baseline (Table 4)

Table 2. Distribution of detailed measures $(\mathrm{cm})$ related to different feed barrier types in 232 free stall herds ${ }^{1}$

\begin{tabular}{lcccc}
\hline Variable & $\begin{array}{c}\text { Post-and-rail } \\
(\mathrm{n}=115)^{2}\end{array}$ & $\begin{array}{c}\text { Headlock } \\
(\mathrm{n}=25)\end{array}$ & $\begin{array}{c}\text { Tombstone } \\
(\mathrm{n}=79)\end{array}$ & $\begin{array}{c}\text { Diagonal } \\
(\mathrm{n}=13)\end{array}$ \\
\hline Top rail height & $113(89-134)$ & $138(120-154)$ & $128(95-153)$ & $138(130-150)$ \\
Concrete manger front height & $56(27-74)$ & $45(25-73)$ & $44(19-61)$ & $49(30-76)$ \\
Manger depth & $40(20-58)$ & $32(13-55)$ & $29(14-53)$ & $33(16-50)$ \\
Inclining rail & $17(0-45)$ & $2(0-15)$ & $1(0-20)$ & $4(0-17)$ \\
Feed table depth & $31(-5$ to 56$)$ & $21(0-40)$ & $24(0-49)$ & $23(0-36)$ \\
Manger brisket & $4(0-43)$ & $7(0-45)$ & $3(0-33)$ & $6(0-50)$ \\
Feed table width & $274(150-500)$ & $250(107-470)$ & $229(240-450)$ & $270(200-459)$ \\
Curb height & $11(1-23)$ & $8(1-21)$ & $9(4-21)$ & $8(2-16)$ \\
Curb width & $49(10-165)$ & $43(20-155)$ & $60(11-160)$ & $43(15-70)$ \\
\hline
\end{tabular}

${ }^{1}$ Each column contains the mean and the minimum and maximum value found.

${ }^{2}$ These numbers are from the post-and-rail barrier only herds. In some of these herds (29), a combination of barriers was found. This table presents data only for the most prevalent feed barrier type on each herd. 
Table 3. Prevalence (\%) of skin lesions on the necks of cows across 3 different categories of feed barrier used in Norwegian free stalls ${ }^{1}$

\begin{tabular}{lccc}
\hline Item & $\begin{array}{c}\text { No lesions } \\
(\mathrm{n}=1,833)\end{array}$ & $\begin{array}{c}\text { Hair loss } \\
(\mathrm{n}=357)\end{array}$ & $\begin{array}{c}\text { Swollen } \\
(\mathrm{n}=144)\end{array}$ \\
\hline Feed barrier & & & \\
Post-and-rail design only $(\mathrm{n}=872$ cows $)$ & 58 & 28 & 14 \\
Vertical feed barrier $(\mathrm{n}=1,168$ cows $)$ & 96 & 4 & 0 \\
Combination $(\mathrm{n}=295$ cows $)$ & 70 & 22 & 8 \\
Total assessed $(\mathrm{n}=2,335$ cows $)$ & 79 & 15 & 6 \\
\hline
\end{tabular}

${ }^{1}$ Herd effect is large but not accounted for in this table.

and an average milk production of $6,858 \mathrm{~kg}$. Tall cows had more neck lesions in farms with top barriers of 98 to $109 \mathrm{~cm}$. When comparing cows of increasing shoulder heights, the probability of neck lesions increased exponentially (Figure 5).

Milk Production. In herds with post-and-rail barriers, the estimated odds, according to the model (Table 4 ), for neck lesions were 2.2 times greater for cows at or below the 10th percentile of milk production level $(5,700$ $\mathrm{kg}$ ) compared with cows at or above the 90th percentile of milk production level $(8,300 \mathrm{~kg} ; P=0.02)$.

Farmers' Attitudes Toward Animals. The response rate to this question was $54 \%$ (63/115 farms with post-and-rail barriers). Out of these responses, $73 \%$ totally agreed or agreed with the statement "animals experience physical pain as humans do" and $9 \%$ neither agreed nor disagreed. The remaining $18 \%$ either disagreed or totally disagreed. When including the farmers who did not respond as a separate category, the percentage of farmers that agreed or disagreed with the statement was reduced to $39 \%$. Farmers who disagreed had odds almost twice as high of having cows with neck lesions as those that agreed with this statement. Attitudes explained a small part of the variation in the model. However, when including the answers from the statement in the model, the cluster effect at herd level was reduced by $3.9 \%$ and a significantly better fit was also achieved.

\section{Vertical Feed Barriers}

A different pattern emerged when analyses were carried out to identify risk factors in farms with vertical feed barriers. Only $4 \%$ of cows in herds with vertical barriers had neck lesions. Among the various vertical barriers, only the diagonal barrier (Figure 2) was a risk factor associated with neck lesions. Our analyses found an interaction between the height of the manger front and the type of vertical barriers (Table 5). The odds of neck lesions were greater among cows using diagonal barriers than those using other vertical barriers, particularly when the manger front height increased above $30 \mathrm{~cm}$.
The estimates of association between milk production and vertical feed barriers were the opposite when compared with the model with post-and-rail herds. In herds with vertical feed barriers, the odds of lesions increased 1.8 times for every $1,000-\mathrm{kg}$ unit increase in milk production (Table 4).

\section{DISCUSSION}

The prevalence of neck lesions was higher in our study than in studies performed in free stalls in Switzerland (Busato et al., 2000) and Canada (Zurbrigg et al., 2005) but lower than in a study carried out in the United Kingdom (Huxley et al., 2004). Our results showed that neck lesions are strongly associated with the top rail in a post-and-rail system. However, although some herds using a post-and-rail system had a very high prevalence of neck lesions, in other herds using the same system, none of the cows had neck lesions. Risk factors in herds with post-and-rail systems were mainly related to the height of the top rail, manger front heights, and the absence of feed stalls. An interaction between top rail height and shoulder height of cows was identified. When such an interaction term occurs, it is possible to predict the probability of skin lesions occurring, for an average cow in an average herd, where only one of the variables in the model can vary. This is calculated when the model is finished and is a technique used to test how well the model can predict the observed data (Dohoo et al., 2009). The predicted probability of neck lesions increased exponentially with increasing shoulder height. Although a very low top rail height might be expected to be a risk factor, this was not found in the current study. A very low top rail height may result in pressure being placed on a location other then the neck and thus prevent animals from reaching for food.

Few Norwegian herds followed documented recommendations regarding the top rail height; however, it should be noted that the Norwegian recommendations mirror those made for Holstein-Friesian cattle. Zurbrigg et al. (2005) reported that for Holsteins the height of the top rail in tie stalls should be below 99 $\mathrm{cm}$ or above $114 \mathrm{~cm}$ to reduce the number of skin le- 
sions. Dumelow (1987) and Huxley and Whay (2006) recommended that the top rail height should be 126 or $130 \mathrm{~cm}$, respectively, to minimize the pressure between the neck and the barrier. Among the Norwegian herds, only $2 \%$ had a top rail height above $126 \mathrm{~cm}$. Others have indicated that an inclining rail should be situated at a distance of $20 \mathrm{~cm}$ toward the feed area (Gjestang, 1982). The main breed in our study was the Norwegian Red, which has a lower mean shoulder height (133.6 $\mathrm{cm})$ than Holstein-Friesian cattle $(147 \mathrm{~cm})$. These data indicate that barrier design should take into account the size of the cows in the individual herds and that the recommendations should reflect this. In the United Kingdom, the use of bendable post-and-rail barriers is recommended (Huxley and Whay, 2006).

In our study, manger fronts higher than $63 \mathrm{~cm}$ reduced the risk of neck lesions in herds with post-andrail barriers. The presence of a concrete manger front was the strongest variable associated with neck lesions. This may be because a high manger front prevents

Table 4. Estimated coefficients $(\beta)$ with SE and odds ratios (OR) with $95 \%$ CI for risk factors in farms with post-and-rail feed barriers ${ }^{1}$

\begin{tabular}{|c|c|c|c|c|c|c|c|}
\hline \multirow[b]{2}{*}{ Fixed effect ${ }^{2}$ and class } & \multirow[b]{2}{*}{ Cows (n) } & \multirow[b]{2}{*}{$\beta$} & \multirow[b]{2}{*}{$\mathrm{SE}$} & \multirow[b]{2}{*}{$\mathrm{OR}^{2}$} & \multicolumn{2}{|c|}{$95 \% \mathrm{CI}$} & \multirow[b]{2}{*}{$P$-value } \\
\hline & & & & & Lower & Upper & \\
\hline Intercept & 1,148 & -1.43 & 0.88 & - & - & - & 0.104 \\
\hline Concrete manger front height $(\mathrm{cm})$ & 1,148 & & & & & & \\
\hline $19-51$ & 287 & 1.89 & 0.34 & 6.59 & 3.37 & 12.90 & $<0.001$ \\
\hline $52-62$ & 597 & 1.26 & 0.28 & 3.54 & 2.04 & 6.15 & $<0.001$ \\
\hline $63-76$ & 264 & 0.00 & - & 1.00 & & & \\
\hline \multicolumn{8}{|l|}{ Feed stalls } \\
\hline Yes & 80 & -2.43 & 0.59 & 0.09 & 0.03 & 0.28 & $<0.001$ \\
\hline No & 1,068 & 0.00 & - & 1.00 & - & - & - \\
\hline \multicolumn{8}{|l|}{ Interaction term } \\
\hline \multicolumn{8}{|l|}{ Top rail height $(\mathrm{cm})$} \\
\hline$<98$ & 60 & -0.43 & 0.64 & 0.65 & 0.18 & 2.29 & $\mathrm{NS}^{2}$ \\
\hline 98-109 & 803 & 1.26 & 0.28 & 3.52 & 2.03 & 6.10 & $<0.001$ \\
\hline$>109$ & 285 & 0.00 & - & 1.00 & - & - & - \\
\hline Cow shoulder height $/ 10 \mathrm{~cm}(\mathrm{~cm})^{3}$ & 1,148 & 0.17 & 0.34 & 1.19 & 0.60 & 2.33 & NS \\
\hline Top rail height $<98$ & 60 & -0.65 & 0.82 & 0.52 & 0.11 & 2.58 & NS \\
\hline Top rail height $98-109$ & 803 & 1.09 & 0.43 & 2.98 & 1.27 & 6.97 & 0.012 \\
\hline Top rail height $>109$ & 285 & 0.00 & - & 1.00 & - & - & - \\
\hline \multicolumn{8}{|l|}{ Mixed ration } \\
\hline Yes & 123 & 1.24 & 0.40 & 3.45 & 1.59 & 7.50 & 0.002 \\
\hline No & 814 & 0.00 & 0.00 & 1.00 & & & \\
\hline Missing & 211 & 0.05 & 0.39 & 1.05 & 0.49 & 2.26 & NS \\
\hline \multicolumn{8}{|l|}{ DIM $^{4}$} \\
\hline-60 to 29 & 160 & 0.00 & - & 1.00 & - & - & - \\
\hline $30-445$ & 840 & 0.64 & 0.22 & 1.89 & 1.22 & 2.91 & 0.004 \\
\hline Missing & 148 & 0.47 & 0.32 & 1.60 & 0.86 & 3.00 & NS \\
\hline Milk production/1,000 kg & 1,148 & -0.31 & 0.11 & 0.73 & 0.59 & 0.91 & 0.005 \\
\hline \multicolumn{8}{|l|}{ Feeding frequency (times/d) } \\
\hline$\geq 3$ & 586 & 0.65 & 0.24 & 1.91 & 1.19 & 3.07 & 0.007 \\
\hline$\overline{\leq} 2$ & 286 & 0.00 & - & 1.00 & & & \\
\hline Missing & 276 & 0.45 & 0.42 & 1.57 & 0.69 & 3.54 & NS \\
\hline \multicolumn{8}{|l|}{ Post-and-rail design } \\
\hline Post-and-rail design only & 863 & 0.00 & - & 1.00 & - & - & - \\
\hline Combinations of barriers present ${ }^{5}$ & 285 & -0.50 & 0.21 & 0.60 & 0.40 & 0.91 & 0.017 \\
\hline \multicolumn{8}{|l|}{ Attitude $^{6}$} \\
\hline Totally disagree and disagree & 113 & 0.61 & 0.29 & 1.85 & 1.05 & 3.25 & 0.033 \\
\hline Indifferent, agree, and totally agree & 504 & 0.00 & - & 1.00 & - & - & - \\
\hline Missing & 531 & 0.07 & 0.21 & 1.07 & 0.71 & 1.63 & NS \\
\hline Herd level $^{7}$ & 1,148 & 0.50 & 0.12 & 1.66 & 1.31 & 2.09 & $<0.001$ \\
\hline
\end{tabular}

${ }^{1}$ The binomial model, including herd as cluster for presence of neck lesion, was used for these calculations. ${ }^{2} \mathrm{NS}=P>0.10$.

${ }^{3}$ Shoulder heights were centered on the mean. This was performed to avoid unrealistic estimates of a cow at 0 $\mathrm{cm}$ height.

${ }^{4} \mathrm{DIM}$ on the day of registration.

${ }^{5}$ When more than one type of barrier was present representing more than $10 \%$ of barriers or barrier space.

${ }^{6}$ Farmers' assessment of the following statement on a 5-point scale, from totally disagree to totally agree: "Animals feel physical pain as humans do" (Kielland et al., 2010).

${ }^{7}$ Clustered on herd level. 


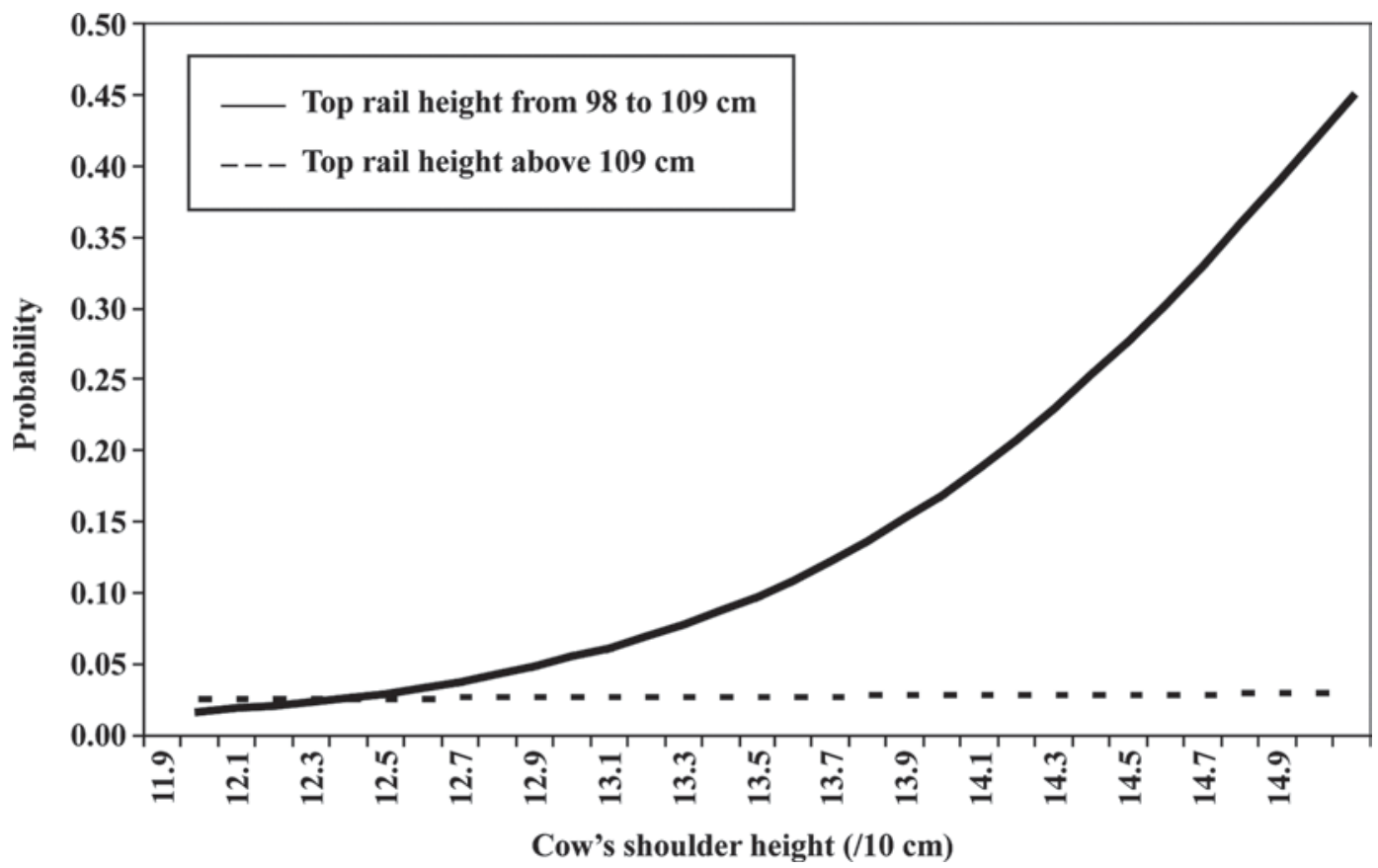

Figure 5. The estimated probability of skin lesions at 2 different top rail heights (TRH). The solid line represents TRH from 98 to 109 $\mathrm{cm}$ and the dotted line represents TRH of $109 \mathrm{~cm}$ and above. The interaction term was between cows' shoulder height (per $10 \mathrm{~cm})$ and TRH. Assumptions about herds were as follows: average milk production of $6,858 \mathrm{~kg}$, concrete manger front $>62 \mathrm{~cm}$, fed fewer than 3 times daily, had no feed stall, fed no mixed ration, cows -60 or +30 DIM, only post-and-rail barrier present, and farmers agreed with the statement "animals experience physical pain as humans do."

cows from reaching far into the feed area by creating a physical barrier between the manger front and the top of the metacarpus, indirectly reducing the contact between the neck and top rail. We are not aware of other studies that have reported an association between different manger fronts and neck lesions. Huxley and Whay (2006) recommended that the manger front should be $64 \mathrm{~cm}$, but data were not provided to justify this figure.

Low feeding frequency was strongly associated with neck lesions, indicating that feeding 3 or more times daily reduces the odds of neck lesions. We suggest that if the feeding frequency is increased, then the competi- tion between cows during feeding is reduced. Therefore, fewer cows are displaced and the cows have more preferred feed sites within comfortable reach. This suggestion assumes that desire for food overrides any potential discomfort from pressure between the neck and top rail that occurs during feeding. DeVries et al. (2005) found that increased frequency of feeding decreased displacement of subordinate cows. They also found that frequent feeding reduced the amount of sorting. This supports our findings that other types of roughage feeding systems are not a risk factor for presence of neck lesions compared with mixed rations. Feeding a TMR might lead to more sorting (Hulsen, 2005). Both more

Table 5. Estimated coefficients ( $\beta$ ) with SE and odds ratios (OR) with $95 \%$ CI for risk factors in farms with exclusively vertical barriers ${ }^{1}$

\begin{tabular}{|c|c|c|c|c|c|c|c|}
\hline \multirow[b]{2}{*}{ Fixed effect and class } & \multirow[b]{2}{*}{ Cows $(\mathrm{n})$} & \multirow[b]{2}{*}{$\beta$} & \multirow[b]{2}{*}{$\mathrm{SE}$} & \multirow[b]{2}{*}{ OR } & \multicolumn{2}{|c|}{$95 \% \mathrm{CI}$} & \multirow[b]{2}{*}{$P$-value } \\
\hline & & & & & Lower & Upper & \\
\hline Intercept & 1,168 & -8.08 & 1.60 & & & & $<0.001$ \\
\hline Tombstone and concrete manger front $31-50 \mathrm{~cm}$ & 1,038 & 0.00 & 0.00 & 1.00 & & & \\
\hline Diagonal and concrete manger front $<30 \mathrm{~cm}$ & 10 & 1.32 & 0.36 & 3.73 & 1.85 & 7.53 & $<0.001$ \\
\hline Diagonal and concrete manger front $31-50 \mathrm{~cm}$ & 60 & 1.73 & 0.62 & 5.67 & 1.68 & 19.08 & 0.005 \\
\hline Diagonal and concrete manger front $>50 \mathrm{~cm}$ & 60 & 1.98 & 0.58 & 7.23 & 2.32 & 22.60 & $<0.001$ \\
\hline Milk production $/ 1,000 \mathrm{~kg}$ & 1,168 & 0.61 & 0.22 & 1.83 & 1.20 & 2.80 & 0.005 \\
\hline Herd level & 1,168 & 1.73 & 0.84 & 5.64 & 1.09 & 29.10 & 0.039 \\
\hline
\end{tabular}

${ }^{1}$ The binomial model, including herd as cluster for presence of neck lesion, was used for these calculations. 
time spent sorting and a possible increase in pressure against the top rail could be explanations for why low feeding frequency increases the risk of neck lesions.

Cows in herds with feed stalls had a lower odds of neck lesions. This could be because separating the cows allows each individual cow to obtain its fair share of roughage. Fewer observations of bullying and displacements during feeding have been reported when cows were fed separately (Hansen et al., 2001; DeVries and von Keyserlingk, 2006), indicating a link between bullying, displacements, and neck lesions.

In herds with post-and-rail barriers, the odds of neck lesions were greater for lower producing cows than for higher producing cows. In contrast, in herds with vertical feed barriers, the odds of lesions were greater among higher producing cows. One possible explanation of why lower producing cows in herds with postand-rails were at increased risk of neck lesions may be that these cows are subordinate and do not manage to obtain the best of the feed provided. Endres et al. (2005) found more displacements at post-and-rail feed barriers than at headlock feed barriers, and others have found that dominant cows sort out the best food, probably resulting in reduced quality food for subordinate cows (Cook and Nordlund, 2004). The use of a barrier that provides some physical separation between cows has been recommended to reduce competition at the feed barrier (Huzzey et al., 2006). Further studies on behavior during feeding, combined with measuring feed intake of subordinate cows at various feeding barriers, could give better insight into this matter.

In the present study, a negative response to the statement "animals experience physical pain as humans do" was associated with an increased risk of neck lesions in the herd. A similar association has previously been found between response to the same statement and skin lesions on legs (Kielland et al., 2009). Our results indicate that the attitude statement succeeds in capturing a farmer effect. A response to one statement in a questionnaire cannot provide a full attitude profile; however, it may offer some insight into how farmers handle their animals (Kielland et al., 2010). An association was also found between management, such as feeding frequency, and this statement. This finding complements the reduced herd-level effect that occurred when attitude was included in the model. Altogether, our findings support the hypothesis that attitudes influence a farmer's management style.

\section{CONCLUSIONS}

A high prevalence of neck lesions was found in herds with a post-and-rail barrier design and a low prevalence was found in herds with vertical barriers. Of all herds assessed, no neck lesions were present on cows in only $48 \%$ of the herds, indicating large potential for improvements. To minimize the risks of neck lesions, post-and-rail barriers should have a manger front above $63 \mathrm{~cm}$ and a top rail higher than $109 \mathrm{~cm}$ in herds that have cows with an average shoulder height larger than $126 \mathrm{~cm}$. In herds with diagonal barriers, the odds of lesions were larger when the manger front increased compared with tombstone barriers. Feeding roughage at least 3 times or more daily, especially when using mixed rations, minimized the odds of neck lesions, as did feed stalls. In summary, feed barriers and feeding regimens are important with respect to skin lesions, as are individual animal traits and some attitudes of the farmer.

\section{ACKNOWLEDGMENTS}

The authors thank the participating farmers and technicians, Hans Kristian Hansen and Stine Kvivesen (The Nord-Trøndelag University College, Steinkjer, Norway), for their help and support during the trial. Access to the data was provided by the Norwegian Dairy Herd Recording System (NDHRS) and the Norwegian Cattle Health Services (NCHS), both in Ås, Norway, according to agreement number 3/2006. The study was financially supported by grants from the Research Council of Norway (15\%), Agricultural Agreement Research Fund (16\%), and the Foundation for Research Levy on Agricultural Products (69\%), all in Oslo, Norway.

\section{REFERENCES}

Anderson, N. 2008. Free stall dimensions for dairy cows. http://www. omafra.gov.on.ca/english/livestock/dairy/facts/info_fsdimen.htm Accessed Feb. 2, 2010.

Barkema, H. W., J. D. V. Ploeg, Y. H. Schukken, T. J. G. M. Lam, G. Benedictus, and A. Brand. 1999. Management style and its association with bulk milk somatic cell count and incidence rate of clinical mastitis. J. Dairy Sci. 82:1655-1663.

Breuer, K., P. H. Hemsworth, J. L. Barnett, L. R. Matthews, and G. J. Coleman. 2000. Behavioural response to humans and the productivity of commercial dairy cows. Appl. Anim. Behav. Sci. 66:273-288.

Busato, A., P. Trachsel, and J. W. Blum. 2000. Frequency of traumatic cow injuries in relation to housing systems in Swiss organic dairy herds. J. Vet. Med. A Physiol Pathol Clin Med 47:221-229.

Carey, V. I. N. C., S. L. Zeger, and P. E. T. E. Diggle. 1993. Modeling multivariate binary data with alternating logistic regressions. Biometrika 80:517-526.

Coleman, G. J., P. H. Hemsworth, and M. Hay. 1998. Predicting stockperson behaviour towards pigs from attitudinal and jobrelated variables and empathy. Appl. Anim. Behav. Sci. 58:6375 .

Cook, N. B., and K. V. Nordlund. 2004. Behavioral needs of the transition cow and considerations for special needs facility design. Vet. Clin. North Am. Food Anim. Pract. 20:495-520.

DeVries, T. J., and M. A. von Keyserlingk. 2006. Feed stalls affect the social and feeding behavior of lactating dairy cows. J. Dairy Sci. 89:3522-3531. 
DeVries, T. J., M. A. von Keyserlingk, and K. A. Beauchemin. 2005. Frequency of feed delivery affects the behavior of lactating dairy cows. J. Dairy Sci. 88:3553-3562.

DeVries, T. J., M. A. von Keyserlingk, and D. M. Weary. 2004. Effect of feeding space on the inter-cow distance, aggression, and feeding behavior of free-stall housed lactating dairy cows. J. Dairy Sci. $87: 1432-1438$.

Dohoo, I., W. Martin, and H. Stryhn. 2009. Veterinary Epidemiologic Research. S. M. Mc Pike, ed. AVC Inc., Charlottetown, Prince Edward Island, Canada.

Dumelow, J. 1987. Development of a new design of cattle feeding barrier. Farm Building Eng. 4:25-27.

Dyce, K. M., W. O. Sack, and C. J. G. Wensing. 1996. Veterinary Anatomy. W. B. Saunders Company, Philadelphia, PA.

Edmonson, A. J., I. J. Lean, L. D. Weaver, T. Farver, and G. Webster. 1989. A body condition scoring chart for Holstein dairy cows. J. Dairy Sci. 72:68-78.

Endres, M. I., T. J. DeVries, M. A. G. von Keyserlingk, and D. M. Weary. 2005. Short communication: Effect of feed barrier design on the behavior of loose-housed lactating dairy cows. J. Dairy Sci. 88:2377-2380.

Gjestang, K. E. 1982. Feeding table geometry in relation to dairy cow comfort. Pages 433-437 in Proc. Second International Livestock Symposium. American Society of Agricultural Engineers, Ames, IA.

Hansen, K., J. S. Strom, and M. Levring. 2001. Feeding space in free stalls. Grøn Viden 21:2-8.

Haskell, M. J., L. J. Rennie, V. A. Bowell, M. J. Bell, and A. B. Lawrence. 2006. Housing system, milk production, and zerograzing effects on lameness and leg injury in dairy cows. J. Dairy Sci. 89:4259-4266.

Hemsworth, P. H., G. J. Coleman, J. L. Barnett, and S. Borg. 2000 Relationships between human-animal interactions and productivity of commercial dairy cows. J. Anim. Sci. 78:2821-2831.

Hulsen, J. 2005. Cow Signals. 1st ed. Roodbont, Zutphen, the Netherlands.
Huxley, J., and H. R. Whay. 2006. Cow based assessments part 3: Locomotion scoring, claw overgrowth and injuries associated with farm furniture. UK Vet 11:1-6.

Huxley, J. N., J. Burke, S. Roderick, D. C. J. Main, and H. R. Whay. 2004. Animal welfare assessment benchmarking as a tool for health and welfare planning in organic dairy herds. Vet. Rec. 155:237239

Huzzey, J. M., T. J. DeVries, P. Valois, and M. A. von Keyserlingk. 2006. Stocking density and feed barrier design affect the feeding and social behavior of dairy cattle. J. Dairy Sci. 89:126-133.

Kielland, C. O. Østerås, E. Skjerve, and A. J. Zanella. 2010. Dairy farmer attitudes and empathy toward animals are associated with animal welfare indicators. J. Dairy Sci. 93:2998-3006.

Kielland, C., L. E. Ruud, A. J. Zanella, and O. Østerås. 2009. Prevalence and risk factors for skin lesions on legs of dairy cattle housed in freestalls in Norway. J. Dairy Sci. 92:5487-5496.

Main, D. C., H. R. Whay, L. E. Green, and A. J. Webster. 2003. Effect of the RSPCA Freedom Food Scheme on the welfare of dairy cattle. Vet. Rec. 153:227-231.

Østerås, O., H. Solbu, A. O. Refsdal, T. Roalkvam, O. Filseth, and A. Minsaas. 2007. Results and evaluation of thirty years of health recordings in the Norwegian dairy cattle population. J. Dairy Sci. 90:4483-4497.

Regula, G., J. Danuser, B. Spycher, and B. Wechsler. 2004. Health and welfare of dairy cows in different husbandry systems in Switzerland. Prev. Vet. Med. 66:247-264.

Thomsen, P. T., S. Ostergaard, J. T. Sorensen, and H. Houe. 2007. Loser cows in Danish dairy herds: Definition, prevalence and consequences. Prev. Vet. Med. 79:116-135.

Weary, D. M., and I. Taszkun. 2000. Hock lesions and free-stall design. J. Dairy Sci. 83:697-702.

Zurbrigg, K. 2006. Sow shoulder lesions: Risk factors and treatment effects on an Ontario farm. J. Anim. Sci. 84:2509-2514.

Zurbrigg, K., D. Kelton, N. Anderson, and S. Millman. 2005. Stall dimensions and the prevalence of lameness, injury, and cleanliness on 317 tie-stall dairy farms in Ontario. Can. Vet. J. 46:902-909. 